\title{
The Empirical Study on Development Value Identity and Requirement of Central Plains Folk Custom Sports Cultural Resources
}

\author{
Fenglian Deng \\ Physical Education College, Nanyang Normal University, Nanyang, Henan, China \\ Email: fengliandeng@126.com \\ Received 2012
}

\begin{abstract}
Utilizing the methods of documentary research, fieldwork, expert interviwing and so on, this paper have taken much survey in terms of cognition and value identity situation of Central Plains folk custom sports culture, the motivation of attending this activity, the development requirement trend and this culture heritage development and creation requirement trend and so on to realize the value identity and requirement of Central Plains folk custom sports cultural resources development from the public, further to wake up the attention from the public about this cultural resources which provide the culture and heritage protection, ecnomic constructure and culture constrcture with theoretical references and practical instruction.
\end{abstract}

Keywords: Folk Custome Sports; Resource Development; Cultural Heritage Protection

\section{Introduction}

Central Plains is considering as the main birthplace of the Chinese nation, is the cradle as well which once be supposed to be the political, ecnomic and cultural centre for a long time in history $_{[1]}$ where gradually formed into Centre Plains culture after thousands of years' civilization. Folk custom sports is reffering to a kind of sports handed dowm from folk custom, folk culture and folk live style; a kind of special cultural morphology going with and satisfy various needs ${ }_{[2]}$; a kind of special sports cultural morphology created by the public and thus enjoyed and passed down by the public ${ }_{[3]}$. Region and folk-custom are the main characteristics of folk custom sports. There must be differences in characteristics and forms of folk custom sports refferring to the different custom habit ${ }_{[4]}$. Centre Plains folk custom sports cultural resource is a kind of activity content of accumulation from Centre Plains folk custom activity, spreading in festival, marriage, funeral, custom carnival and custom amusement with local feature and national style in terms of body building, amusement, performance and sporting competition.

Culture value system with modern meaning morphology is under construction. Culture is becoming the spirit power and need of time of cultural construction. This paper aiming at understanding the value identity and requirement of Central Plains folk custom sports cultural resources development from the public, further to wake up the attention from the public about this cultural resources which provide the culture and heritage protection, ecnomic constructure and culture constrcture with theoretical references and practical instruction.

\section{Survey Object and Study Method}

\section{Survey Object}

The basic situation of the poll is devided into the following:

"By the soft science research project in henan province: (112400450111). sex ratios; age sections; education backgroud announcement; occupation announcement; habitation;economic salary distribution.

\section{Study Method}

1).Documentary research method

The considerable document and materials were accomulated via internet and disc index, consulting history materials and the refferring books to understand the existing study accompulishment to lay the foundations.

2). Survey method

a). Fieldwork method

Observing the situation when people took the folk custom sports at morning and evening practice and to gain material at first hand by investigating on the spot.

b). Expert interview method

Experts in folk custom, history, sports and folk actors were consulted to gain much more precious materials.

c). Questionnaire method

The questionnaires were mainly extended in cities, towns and countries in Kaifeng, Luoyang, Zhenghou, Shangqui and Nanyang in Henan province at the morning and evening practice involving Public Sports Administration, teachen in folk custom sports, culture station and folk actors with each area 2000 questionnaires with effective percentage reaching $89.5 \%$.

d). Statistics method

SPSS software were adopted to classify and mathematially counte the questionnaires and colleced materials in convention.

\section{The Result and Analysis of the Survey}

\section{The Survey of Cognition of Centra Plains Folk Cutstom Sports Culture and Value Identity from the Public}

Cognition signifies an activity which people acquire know- 
ledge by recognizing the objective things $\mathrm{s}_{[5]}$. Cognition of Central Plains sports means the understandinig of its program, value and knowledge which are knowledge reserve and mental preparation to attend this activity. The level of cognition directly influence the public's participation initiative and enthusiasm. So that, some question were set such as "Do you know what folk custom sports is?", "Have you been attened or seen folk custom sports?”, "When do you know any program about folk custom sports?". The result shows that there is no obvious difference in cognition among people in different age, occupation, ecnomic salarty but quite obvious among people in different level of education, health condition and residences. There were $86 \%$ people aged above 36 years old know what folk custom sports is, $79 \%$ people had participated sports culture tourism. The people with good health condition accounted for high proportioin of the total number who participated folk custom sports activity.

Value identity means a procedure which constantly alte its own value construction by value cognition,value evaluation and value selection, internalize as its own value orientation about social value sense in some degree and value correctness, and then outernalize a certain value behavior, then perform as the shape of joint value sense with congruity and unity of value ideal, value orientation and value standared and so on from social members ${ }_{[6]}$. Form 1 shows that the public in city, towm and country show their cognition about amusement value which primary value is riching culture life in spare-time which proporation takes $93.6 \%$ in city, $96.5 \%$ in town and $98.6 \%$ in country. Inheriting national culture and custom ranks the second which proporation takes $96.7 \%$ in country and reach 88.3 in city as well which represents that Central Plains folk custom sports culture has extremely crucial value in inheriting national culture in country. The proportation of the value of strengthening comunication accounts for above $87 \%$ which shows the important effect to strengthen communication in public. Body-building ranks the fourth. What's more, there is a lack of understanding of education valuce of folk custom sports culture which is same as the worry of education culture section.

Having ackonwledged about this situation, the refferring section came to develop pilot zone in Central Plains, such as folk custom sports education plan in some high school in Kaifeng and Nanyang city, dragon-dance and lion-dance performace in physical teaching practise in PE. College of Henan Normal University, YangKo, waist drum and Taiji Fan selected in teaching content in Nanyang Normal College.

As a matter of fact, the public have cognition of amusement value, inheriting national cultrue custom value, strengthening communication, body-building of folk custom sports culture but lack control value which propaganda and guide is to be strengthened.

\section{The Motivation Survey of Attending Folk Custom Sports Culture Activity}

The motivation is the primary power inducing behavior. Form 2 shows that amusement ranks top in the main motivation of folk custom sports culture which proportion takes 95\% in city, $92 \%$ in town and $93 \%$ in country. Following custom habit ranks the second which proportion takes $79 \%$ in city, $86 \%$ in town and $95.3 \%$ in country. The personal favor ranks the third in country which proporation takes $91 \%$, followed by accelerating communication and body-bulding which proportion respectively takes $90.1 \%$ and $76 \%$. While the proportion of cultivating offspring and adding salary is low. Body-buildinig ranks the second in city followed by following custom habit, personal favor and accelerating communication. While adding salary by commercial way and cultivating offspring are fallen behind.

The public shows much interesting in Central Plains custom sports culture, especially in country, with sense of national pride and eomtion identity. the direct motivation could boil down to amusement communication and custom habit. The public in town have acknowledged body-building value and thus take it as an important body-building way. The smaller proportion of adding salary shows they lack obvious income creation capacity.

All in all, the main motivation contains amusement, following national habit, personal favor, accelerating communication and body-building.

\section{The Survey of Need Trend of Developing Central Plains Folk Custom Sports Cultural Resources from the Public}

The public attending Central Plains folk custom sports culture activity not only depend on personal idea, personal need and personal condition, but also based on accommodate degree of social environment and a series of support condition it can provide.

Form 1.

The survey of identity of Centra Plains folk cutstom sports culture from the public.

Main funtion Inherite national culture and custom Rich culture life in spare-time Body-building Eduction function Strengthen communication others

\begin{tabular}{|c|c|c|c|c|c|c|}
\hline City & 88.3 & 93.6 & 96.8 & 47.3 & 92.3 & 2.3 \\
\hline Town & 86.5 & 96.5 & 92.3 & 50.1 & 90.1 & 3.4 \\
\hline Country & 96.7 & 98.6 & 86.6 & 64.2 & 87.9 & 5.1 \\
\hline
\end{tabular}

Form 2.

The motivation survey of attending folk custom sports culture activity(\%).

Main course Following national habit Persaonal favor Body building Cultiviting offspring amusement Adding income Accelerating communication other

\begin{tabular}{|c|c|c|c|c|c|c|c|c|}
\hline city & 79 & 78 & 87 & 54.2 & 95 & 48.2 & 76.8 & 3.6 \\
\hline town & 86 & 82 & 81 & 56 & 92 & 43.2 & 81.5 & 5.6 \\
\hline country & 95.3 & 91 & 76 & 66 & 93 & 41.5 & 90.1 & 4.3 \\
\hline
\end{tabular}


Form 3 shows that the public relatively satisfied with Central Plains folk custom sports cultural resource. Based on the data, the public held positive attitude

toward the development of this activity in some degree while around $1 / 3$ of the people not satisfied with it which demonstrates that difference exits between the present situation and the immediate need of the public.

The degree shows the need trend which relativelly derectly show the need variation content and reflect the need condition of Central Plains folk custom sports cultural resource development from lateral ties in the future.

Form 4 shows that strengthening organization and administration and supporting from government are the greatest wish from the public. On one hand, as group activity which need certain participation scale, this culture sports activity needs summons of speicialized recreation and sports mainstay and relative organization. On the other hand, strengthening organization and administration of folk custom sports activity especially need to strengthen great support from sports and culture department.The financial support from the government is very meaningful.

Form 4 shows the anxious attitude of the public towards developing commercial economy such as local tourism by taking advantage of Central Plains folk custom sports cultural resource based on the relatively high proportion of strengthening commercial development. In recent years, folk culture tourism has been to the hot spot in tourism development. Development of commercial activity such as Central Plains folk custom sports cultural tourism become the inevitable choice. The data also shows that there are complex folk custom sports programs in country which eager to be regulated and popularized scientificly and systematicly. While there is relatively higher demand of making supportability policy in town than in country.

The interview shows that there is great wishes of the public in city in regulatory system in terms of finance, ground and facilities which may have something with the relatively higher level of life condition and cognition as a whole

To sum up the above arguments, there is strong needs and wishes of the public to develop Central Plains folk custom sports culural resource which represents the need trend which has important reference value and instruction meanings.

\section{The Need Trend of Inherition, Development and Cre- ation of Central Plains folk Custom Sports Culture from the Public}

The appearance and development of Central Plains folk custom sports culture is a process of traditional culture accumulation. In history and dvelopment light, the need trend must represent a combination of inherition, development and creation. There are three angles to be observed in terms of the need of development of amusement folk custom sports cultural resource from the public, the attitude toward transforming the content of competitive folk custom sports culture and commercial development intention of folk custom sports culture.

1). The need of the development of amusement folk custom sports cultural resource from the public

Amusement folk custom sports activity is one of the main ways of the public's daily life and festival culture activity which is most closely to daily life.

The attitude of reforming folk custom sports culture properly when reserving traditional conten ranks top, which proportion takes $65.2 \%$ in country, $61.6 \%$ in town and $64.2 \%$ in city. The data also means that the public held rational attitude toward the development of amusement folk custom sports cultural resource who agree to reform and development it and put stress on the proper principle.

2) The attitude toward to content reform of competitive folk custom sports culture

Competitive folk custom sports activity hereby means the competitive program and performance program in Games such as wrestle, playing diabolo, dragon-dance, lion-dance, dragonboat race and walking on stilts and some competitive program in public life and festival.

Form 5 shows that the public in country was tend to reserve folk custom and reform properly on that basis. While the public in town and city showed their strong reforming wishes which properly reform propertion reached $57.8 \%$ and $51.6 \%$ respectively, totally reform propertion reached $15.4 \%$ and $26.1 \%$. One of the reason may be that the public in town and city raraly attended village cometitive activities influenced by life environment and the difference in concept and acknowledgement. Overall, the public is tend to reserving national characteristics of competitive folk custom sports culture and should be properly modernized reformed at that basis.

3)The intentiion of commercial development of folk custom sports culture tourism from the public

In terms of reserving national culture tradition and meet the tourists' need, the attitude of the public toward commercial development such as folk custom sports culture tourism reflects the contradiction between incisive traditional concept and economic benefit as a drive.

Form 6 shows that the public put satisfying the tourists' need with proper reform as the first choice no matter in country, town and city which proportion is $97.8 \%, 95.7 \%$ and 96.6 respectively. As mentioned above, the public is more tend to economic benefit fulfillment during the tourism economy development process. But at the same time, the proportiong of keeping cautious and paying attention to cultural heritage protection reachs $84.3 \%, 78.3 \%$ and $80.3 \%$ respectively. The data demonstrates that the public pursues economic benefit when develop folk custom sports culture tourism at the same time shows their contratition attitude toward protection sense. But ultimately the public prefer to reform depending on tourists' willing.

Form 3.

The survey of need trend of developing Central Plains folk custom sports cultural resources from the public (\%).

\begin{tabular}{cccccc}
\hline Situation & Very satisfied & Relatively satisfied & Just so & Not quite satisfied & Unsatisfied \\
\hline City & 11.2 & 36.2 & 29.8 & 26.3 & 10.1 \\
Town & 13.8 & 38.9 & 30.1 & 24.1 & 8.3 \\
Country & 16.9 & 56.1 & 26.9 & 22.5 & 7.6 \\
\hline
\end{tabular}




\section{F. L. DENG}

Form 4.

The need survey of developing Central Plains folk custom sports cultural resource from the public.

\begin{tabular}{|c|c|c|c|c|c|c|c|}
\hline Situation & $\begin{array}{c}\text { Enact } \\
\text { supporting } \\
\text { rules }\end{array}$ & $\begin{array}{c}\text { Strengthen } \\
\text { government support }\end{array}$ & $\begin{array}{l}\text { Strengthen regulation } \\
\text { and extension }\end{array}$ & $\begin{array}{c}\text { Enlarge commercial } \\
\text { development }\end{array}$ & $\begin{array}{l}\text { Strengthen } \\
\text { talents training }\end{array}$ & $\begin{array}{l}\text { Strengthen organization } \\
\text { administration }\end{array}$ & $\begin{array}{l}\text { Strengthen advocacy } \\
\text { and communication }\end{array}$ \\
\hline City & 93.6 & 89.6 & 87.6 & 93.2 & 76.5 & 97.6 & 87.9 \\
\hline Town & 92.3 & 91.5 & 85.1 & 90.5 & 74.3 & 95.2 & 85.3 \\
\hline Country & 90.1 & 95.6 & 90.2 & 87.3 & 68.9 & 93.1 & 80.1 \\
\hline
\end{tabular}

Form 5.

The attitude toward content reform of competitive folk custom sports culture (\%).

\begin{tabular}{ccccc}
\hline $\begin{array}{c}\text { Attitude } \\
\text { situation }\end{array}$ & $\begin{array}{c}\text { Replaced by modern } \\
\text { competitive sports }\end{array}$ & $\begin{array}{c}\text { Popularize totally in } \\
\text { its primary way }\end{array}$ & $\begin{array}{c}\text { Reform properly on basis of reserving } \\
\text { tradition and characteristics }\end{array}$ & $\begin{array}{c}\text { Modernized reform totally integrate with } \\
\text { modern competition in timeing and way }\end{array}$ \\
\hline Country & $1.5 \%$ & $40.1 \%$ & $61.8 \%$ & $8.9 \%$ \\
Town & $1.3 \%$ & $38.7 \%$ & $57.8 \%$ & $15.4 \%$ \\
City & $2.6 \%$ & $29.7 \%$ & $51.6 \%$ & $26.1 \%$ \\
\hline
\end{tabular}

Form 6.

The intentiion of commercial development of folk custom sports culture tourism from the public(\%).

\begin{tabular}{ccc}
\hline Attitude situation & $\begin{array}{c}\text { Keep cautious to protect } \\
\text { folk custom sports }\end{array}$ & $\begin{array}{c}\text { Properly reform to cater the } \\
\text { need of tourists' aesthetic }\end{array}$ \\
Country & 84.3 & 97.8 \\
Town & 78.3 & 95.7 \\
City & 80.3 & 96.9 \\
modern amusement
\end{tabular}

Based on the analysis above, the attitude of the public toward Central Plains folk custom sports culture is quite cauious which mainly focus on properly reforming and developing on the basis of protecting national cultural heritage to meet the need of body-building, leisure activity and amusement.

\section{Conclusion}

With higher cognition degree about Central Plains folk custom sports culture, the public has the relative identity in terms of amusement value, inheriting national culture custom value, strengthen mutual communication and body-building value while lack acknowledgement of control value which is to be propageted and guided.

Amusement, following national habit, personal favor, acce to finance, ground and facilities, celetating communication and body-building in turn compose the main motivation of attending the sports activity.

The public have a strong need and wishes to develop Central Plains folk custom sports cultural resource; There are complex programs which are eager to regulated and popularized scientificly and systematicly; the public in city shows their strong wishes of regulation rules public held rational attitude toward the development of amusement folk custom sports cultural resource who agree to reform and development it and put stress on the proper principle;the public is tend to reserving national characteristics of competitive folk custom sports culture and should be properly modernized reformed at that basis; the public pursues en develop folk custom sports culture tourism when prusuing economic benefit at the same time shows their contratition attitude toward protection sense. But ultimately the public prefer to reform depending on tourists' willing.

\section{REFERENCES}

Zhao Baoyou, Central Culture and its Modern Value. Chinese Ancient and Modern, 2001(5):7

Chinese Physical Science Institute, Physical Science Dictionary[M], Beijing: Academic Press, 2000:180.

Tu Chuanfei, The Study of Folk Custom Sports Characteristics[J], Physical Culture Periodical, 2005(11):133-139.

Wang Tiexin, Chang Naijun, Study Summery of Chinese Folk Custom sports[J]. Physical Culture Periodical, 2009(10):133-139.

Liuchun, Tourism Psychology[M]. Tianjin: Naikai University Press, 2000: 33-34.

Liu Kefang, The Study of Value Identity of Socialism Kernel Value System refferring to College Student, Liaoning Normal University Master Degree Candidate Paper, 2010. 